\title{
Characteristics of Chia (Salvia hispanica L.) Seed Oil Extracted by Ultrasound Assistance
}

\author{
Marta Elvia Rosas-Mendoza, * Jonathan Coria-Hernández, Rosalía Meléndez-Pérez, José Luis Arjona-Román.
}

UNAM. Facultad de Estudios Superiores Cuautitlán, Laboratorio de Análisis Térmico y Estructural de Alimentos. UIM-L13, Carretera Cuautitlán-Teoloyucan Km 2.5, Cuautitlán Izcalli, Edo. Méx. C.P. 54740, México.

* Corresponding autor: PhD. Marta Elvia Rosas Mendoza Tel.: 525 56231999, ext. 39433. Fax.: 525 56231999, ext. 39402 E-mail address:.merosas@unam.mx

Received August 4 $4^{\text {th }}, 2017$; Accepted August 21 $1^{\text {st }}, 2017$

\begin{abstract}
The aims of this work were to evaluate the effect of Ultrasound-Assisted Extraction (UAE) in oil yield, as well as in the physicochemical and chemical characteristics of Chia seed oil. The seeds were cryo ground before extraction; ultrasonic bath at $40 \mathrm{kHz}$ was used during 90 min extraction process. The UEA resulted in intensification of the extraction, with $79.3 \%$ oil yield, while $69.2 \%$ were for stirring extraction. Diffusion coefficient's values were $1.04 \times 10^{-11}$ $\mathrm{m}^{2} \mathrm{~s}^{-1}$ and $9.16 \times 10^{12} \mathrm{~m}^{2} \mathrm{~s}^{-1}$, respectively. From thermal analysis, made with MDSC, the main triacylglycerols (TAG's) transitions were obtained. By ATR-FTIR, changes in the 987 and $968 \mathrm{~cm}^{-1}$ wave numbers, corresponding to the outside plane deformation of $\mathrm{C}-\mathrm{H}$ bonds in unsaturated fatty acids, were obtained. The UEA could change the material properties by cavitation that enhances the mass transfer, but no oil composition.
\end{abstract}

Key words: Chia seed; Oil extraction; Ultrasound; MDSC; FTIR

\section{Introduction}

Salvia hispanica L., whose common name is chia, is an annual herbaceous plant that belongs to the Lamiaceae family, which is native to southern Mexico and northern Guatemala. It has been cultivated from tropical to subtropical regions. It is a possible new crop for food industry. This plant was used by the Aztec tribes in the early history of Mesoamerica. This grain crop was important not only for food, but also for medicines and paints, because its chemical composition that is about $35 \%$ dietetic fibre, $32 \%$ fat, $25 \%$ protein, $6 \%$ moisture and $2 \%$ carbohydrates [1]. Chia oil is a centuries-old ingredient that has been rediscovered for today cosmetics and nutritional applications. Since chia seed oil is a natural product, it has a variable chemical composition depending on several factors such as the cultivation environment and the extraction system [2, 3].

Commercial production of vegetable oils is based on pressing and solvent extraction [4-9], although there are also other methods $[10,11]$. The first is a purely mechanical extraction mode that is performed at low temperature, thus preserving the proportion of essential fatty acids, vitamin E, natural antioxi-
Resumen: Los objetivos de este trabajo fueron evaluar el efecto de la extracción asistida por ultrasonido (UAE) en el rendimiento de aceite, así como en las características físico-químicas y químicas del aceite de semilla de Chia. Las semillas se trituraron antes de la extracción; se utilizó un baño ultrasónico a $40 \mathrm{kHz}$ durante un proceso de extracción de 90 minutos. La UEA dio como resultado una intensificación de la extracción, con un rendimiento de aceite de $79.3 \%$, mientras que $69.2 \%$ fue para extracción con agitación. Los valores del coeficiente de difusión fueron $1,04 \times 10^{-11} \mathrm{~m}^{2} \mathrm{~s}^{-1}$ y $9,16 \times 10^{-12} \mathrm{~m}^{2} \mathrm{~s}^{-1}$, respectivamente. A partir del análisis térmico, realizado con MDSC, se obtuvieron las principales transiciones de triacilgliceroles (TAGs). Por ATR-FTIR, se obtuvieron cambios en los números de onda de 987 y $968 \mathrm{~cm}-1$, correspondientes a la deformación del plano exterior de los enlaces C-H en ácidos grasos insaturados. La UEA podría cambiar las propiedades del material por cavitación, que mejora la transferencia de masa, pero sin cambiar la composición de aceite. Palabras clave: Semilla de Chia; Extracción de aceite; Ultrasonido; MDSC; FTIR

dants and does not require any additives. The seed is partially peeled and cleaned to remove impurities; the clean seed is brought to the press which can be a screw extruder. Here it is especially ensured that the temperature generated by the pressure does not exceed $45^{\circ} \mathrm{C}$ to ensure the molecular stability of the polyunsaturated fatty acids. This also avoids the dissolution of waxes and other substances. For several days the crude oil decants in stainless steel tanks. It is then pumped through a disposable cotton filter and packaged. The solvent extraction method can be applied directly to materials low in crude oil. Here the seeds are treated physically to obtain a smaller size free of shell. They are then subjected to a chemical extraction process, in a Soxhlet equipment or a shaked flask, using different solvents. The amount of oil extracted is maximized by modifying the solvent, the particle size and the extraction time. Then, the oil-solvent mixture obtained is purified by simple distillation. To date, solvent extraction of chia seeds and some scanty data on their composition have been reported, but there is little information about chia seed oil and the influence of the extraction system on its fatty acid (FA) profile and physicochemical characteristics $[12,13]$. 
Application of ultrasound waves in various foods and technical processes has numerous potentials, and is relatively novel and developing. These waves are mechanical waves with a higher frequency than human hearing threshold (higher than 20 $\mathrm{kHz}$ ) and move on the surface or through bulk with a special speed depending on wave and material properties they travel through. Ultrasound-Assisted Extraction (UAE) is one of the most practical and cost-effective applications of ultrasound for extraction processes in the food industry $[14,15]$.

Ultrasound could change the material properties through creating asymmetric pressures, shear stress and localized high temperatures. This is because the sound waves travel in matter, as they involve expansion and compression cycles traveling through a medium. Expansion pulls molecules apart, whereas compression pushes them together. In a liquid, the expansion cycle produces negative pressure. If the ultrasound is strong enough, the expansion cycle can create bubbles or cavities in the liquid. This is so when the negative pressure exerted exceeds the local tensile strength in the liquid, which varies depending on its nature and purity. The process by which vapour bubbles form, grow and undergo implosive collapse is known as "cavitation". The impact of the jets produced by cavitation on the solid surface is very strong. This can result in serious damage to impact zones and can produce newly exposed, highly reactive surface [16].

In tissues where the desired components are located within cells, pre-ultrasound treatment by size reduction to maximize surface area is critical for achieving rapid and complete extraction. It is obvious that reducing the size of the vegetal material particles will increase the number of cells directly exposed to extraction by solvent and thus exposed to ultrasonically induced cavitation. Ultrasound can facilitate swelling and hydration, causing an enlargement in the pores of the cell wall. This will improve the diffusion process and therefore, enhancing mass transfer [17-19]. The cryo-grinding involves the size reduction of the plant, once dried, pre-freezing in liquid nitrogen at $-196^{\circ} \mathrm{C}$. Cooling with cryogenic gases of heat sensitive materials during mechanical grinding process, prevents the temperature increase due to energy transformation of electric motors. Thus the ground substance keeps without melt and stick. Furthermore, the UAE technique was achieved at lower temperatures, which are more favourable for thermally unstable compounds. Thereby ultra-sonication may reduce the dependence on a solvent and enable use of alternative solvents, which may provide more attractive economics, environmental and health and safety benefits [20].

Modulated temperature differential scanning calorimetry (MDSC), which provides more capability than conventional DSC, has been used for thermal characterization of edible oils and fats. The total, reversible and non-reversible heat flows can be quantified during the transition of the samples in one single scan. The reversible and non-reversible signals reveal the thermodynamic and kinetic characteristics of transition, respectively [21]. The most important aspect of the physical properties of oils and fats is related to the solid-liquid and liquid-solid phase changes with temperature; in other words, melting and crystallization, behavior that is two of the important properties for functionality in many prepared food products. Nonetheless, in principle, the thermal profile of edible oils and fats contains a great deal of information regarding the nature of the transition and can serve as a very useful probe for "fingerprinting" a given oil or fat [13]. Also, this technique has been employed with satisfactory results in the determination of the heat capacities $(\mathrm{Cp})$ of organic compounds and fatty acids in vegetables oils and triglycerides (TAG'S) [23]. Chia oil is extremely high in polyunsaturated fatty acids (FA), particularly $\omega 3$ linolenic (50-57\%) and $\omega 6$ linoleic $(17-26 \%)$ acids. On average, the FA ranked in the following order of abundance: $\alpha$-linolenic acid $(\mathrm{Ln})>$ linoleic acid (L) $>$ oleic acid $(\mathrm{O}) \approx$ palmitic acid $(\mathrm{P})>$ stearic acid $(\mathrm{St})>$ vaccenic acid $(\mathrm{Vc})[6,8,9,15,24,25,26]$. Ixtaina et al. [4] have recently shown that twelve triacylglycerol molecular species were identified, most of them with at least one $\alpha$-linolenic acid esterifying the glycerol; trilinolenin $(\alpha \operatorname{Ln} \alpha \operatorname{Ln} \alpha \operatorname{Ln})$ was the major compound.

By the other hand, Infrared (IR) spectroscopy is an old analytical technique that has been widely utilized as a routine tool by the fats and oils industry for FA determination. With Fourier-transform infrared spectroscopy (FTIR), the infrared spectral analysis indicates what types of molecules are present in the sample; since it offers the possibility to measure the vibration types in atomic bonds at different frequencies, functional groups and possible changes in sample structure and concentration can be recognised [27]. The introduction of Attenuated Total Reflectance (ATR, also known as internal reflection) instead of transmission cells, resulted in a new IR procedure that was developed, validated and adopted as official method by AOAC International. In comparative studies, better precision such as lower reproducibility relative standard deviation values were obtained by using the ATR-FTIR method relative to transmission FTIR methods [28].

Recently, chia seed has become important for human health and nutrition because of its important polyunsaturated fatty acids content promotes beneficial health effects. So, the aims of this work were to evaluate the chia oil yield and the physicochemical and chemical properties of oil obtained by UAE as well as the ultrasound effect on the diffusion coefficient.

\section{Materials and Methods}

\subsection{Sample preparation}

Seed mix of black and white chia, from Jalisco state was used; they were purchased in a local market from the same batch and brand. They were cryo-ground in an A11 Basic (Ika Works Inc., Wilmington USA), with an impact knife and liquid $\mathrm{N}_{2}$ for 60 seconds until a flour was obtained. Particle size analysis was conducted in a no rigorous US series of sieves $(20,28,35,48$, $65,100,150$ and 200 meshes) from which the average diameter relative to the surface was calculated. 


\subsection{Oil extraction}

Extracting oil from $10 \mathrm{~g}$ of chia flour was performed using a Soxhlet extractor; petroleum ether was used as solvent in 1:10 proportion, with 6 hours extraction time and kept at 55 $\pm 3{ }^{\circ} \mathrm{C}$. After the extraction, the solvent was removed in a water bath under hood for 30 minutes; then the fat flask was dried in an oven at $100{ }^{\circ} \mathrm{C}$ for $15 \mathrm{~min}$ and weighed to record its mass. The result is expressed as a percentage in crude fat. For extraction by stirring, $10 \mathrm{~g}$ of chia flour for each experiment was weighted, put into a $125 \mathrm{ml}$ Erlenmeyer flask at constant weight and $100 \mathrm{ml}$ of petroleum ether were added. The flask was placed in a thermos-stirring iron MSH20A (Wise Stir, Wertheim, Germany), and the extraction was evaluated at 10, 20, 40, 60 and 90 min of experimental time. Having completed the extraction time, the flask was removed from iron and vacuum filtered in order to retrieve the mass of inert; then the extract was put into a beaker, heating in a hot water bath at $55{ }^{\circ} \mathrm{C}$ for solvent evaporation. After greatly reduce the volume, extract was centrifuged to obtain the mass of extracted oil and inert.

For UAE, the flasks with $10 \mathrm{~g}$ of flour and ether were placed in an ultrasonic bath 8895-04 (Cole Palmer, ILL, USA) at $40 \mathrm{kHz}$ for the same experimental times. The amount of extracted oil was obtained with the equivalent procedure as for stirring samples.

\subsubsection{Statistical analysis}

Each experimental run, was conducted in triplicate. The oil fraction $(X o)$ for each experimental time during extraction was considered to be the response variable. Statistical analyses were performed using MINITAB 16. A two-way ANOVA analysis was applied within experimental runs (each time replication) to verify the mean equality, which was confirmed with an a posteriori Tukey test. With the mean values obtained of extracted oil, the inert solids and extraction yield was computed.

\subsection{Mass Diffusion Coefficient determination}

To obtain the oil diffusion coefficient, only the mean values were considered. For the mass transfer exponential approximation at equilibrium, we assumed first-order kinetics to obtain the concentration equilibrium value [29a]. The solution of Fick's second law for diffusion in a sphere, considering only the first term of the solution series, result in the equation $1[29,30]$ :

$$
\frac{M_{t}}{M_{\infty}}=\frac{C-C_{\infty}}{C_{0}-C_{\infty}}=\frac{6}{\pi^{2}} e^{\left(\frac{-D_{e} \pi^{2} t}{r^{2}}\right)}
$$

$M t / M_{\infty}$ represents the driving force for mass transfer, where $C_{0}$, $C$ and $C_{\infty}$ are the initial, bulk and equilibrium concentrations, respectively; $r$ is the mean particle radio.

\subsection{Optical microscopy}

In order to observe the effect of extraction treatments on chia flour, a micrographs were acquired with a stereo microscopy EZ4D (Leica, Wetzlar, Germany) at 35x, from the residual flour obtained after Soxhlet, stirring and UAE extraction.

\subsection{Thermal analysis by MDSC}

For thermal analysis, a mass fraction of each oil sample $( \pm 6$ $\mathrm{mg}$ ), from different extraction treatments, was placed in hermetic aluminum pans in a MDSC 2920 (TA Instruments, NJ, U.S.A.); this equipment was previously calibrated with Indio and sapphire, for constant cell (1.0538) and heat capacity constant (1.1806), respectively. An empty pan was used as reference. After stabilization at $-50{ }^{\circ} \mathrm{C}$, the samples were heated to $90{ }^{\circ} \mathrm{C}$ at $10^{\circ} \mathrm{C} / \mathrm{min}$ in a nitrogen atmosphere at $60 \mathrm{ml} / \mathrm{min}$. The freezing procedure dictates the structure within the sample, which then dictates thermal behavior. The melting point $(\mathrm{Tm})$, melting enthalpy $(\Delta H)$, and the $C p$ changes in each thermogram were evaluated by the Universal Analysis software V. 4.4A. Each extraction method was analyzed by triplicate samples.

\subsection{FTIR analysis}

Sixteen scans were performed per sample with a Spectrum Frontier FTIR spectrophotometer (Perkin Elmer, MA, USA) from 4000 to $450 \mathrm{~cm}^{-1}$, with the ATR technique.

\section{Results and Discussion}

The mean diameter obtained was of $0.614 \mathrm{~mm}$ for all samples. Soxhlet oil extraction was $3.15 \pm 0.08 \mathrm{~g}$ as the maximum crude fat content $(100 \%)$ in chia seeds. The oil yield from each treatment is shown in Fig. 1. It can be observed that UAE enhanced the extraction process because the mechanical effects of ultrasound provide a greater solvent penetration into cellular materials and improve mass transfer due to the effects of micro streaming. This is combined with the disruption of cell walls to facilitate the release of intracellular product contents $[17,31$, 32]. Another mechanical effect caused by ultrasound may also be the agitation of the solvent used for extraction, thus increasing the contact surface area between the solvent and targeted compounds by permitting greater penetration of solvent into the sample matrix [33]. So it was obtained $79.3 \%$ for the UAE extraction while yield by stirring treatment was $69.2 \%$, at $90 \mathrm{~min}$.

The UAE improved extraction yield of around $10 \%$, although higher gains were in time, as $60 \mathrm{~min}$ almost the same amount of oil was obtained from this treatment compared with 90 min of stirring (Fig. 2).

The ultrasonically induced cavitation was shown to increase the permeability of the plant tissues. The extraction mechanism involves two types of physical phenomena: diffusion through the cell walls and washing out, or rising, the cell contents once the walls are broken. Both phenomena are 


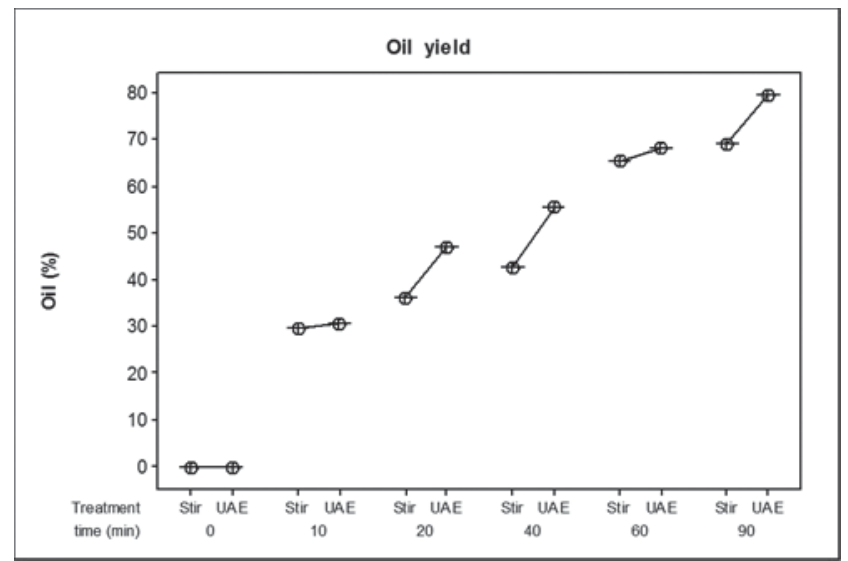

Fig. 1. Oil yield comparison between a stir and UEA treatments.

affected by ultrasonic irradiation. Some cells exist on the form of a glans, external or internal, that is filled with oil. A characteristic of such a gland, when external, is that their skin is extremely thin and can be very easy destroyed by sonication. This explains why the extraction of fat oil is facilitated by sonication and can be seen in Fig. 2, where the kinetics represents a more continuous process, apparently at a constant rate, with less resistance than in stir process. For internal glands, it is the milling degree of the material which plays an important role [19].

In Fig 3 can be observed the effect of extraction method on the sample morphology. Cavitation on the product surface causes impingement by micro-jets that result in surface peeling, erosion and particle breakdown. According to Chemat, Huma \& Khan [34], microfractures and disruption of cell walls provided more evidence for the mechanical effects of ultrasound thus facilitating the release of their contents, in contrast to conventional maceration or solvent extraction. Chia seeds have a mucilage that is a complex carbohydrate of high molecular weight, and an important component of the seed due to its physiological role [35]. The mucilage is secreted when the seed comes into contact with water, generating high-viscosity solutions. It is worth mentioning that the mucilage was not removed from the seed before grinding and extraction. Capitani, Spotorno, Nolasco \& Tomás [36] have shown that mucilage surrounding chia seed has a low oil holding capacity due to the cellulose content, so it is not considered a resistance to extraction.

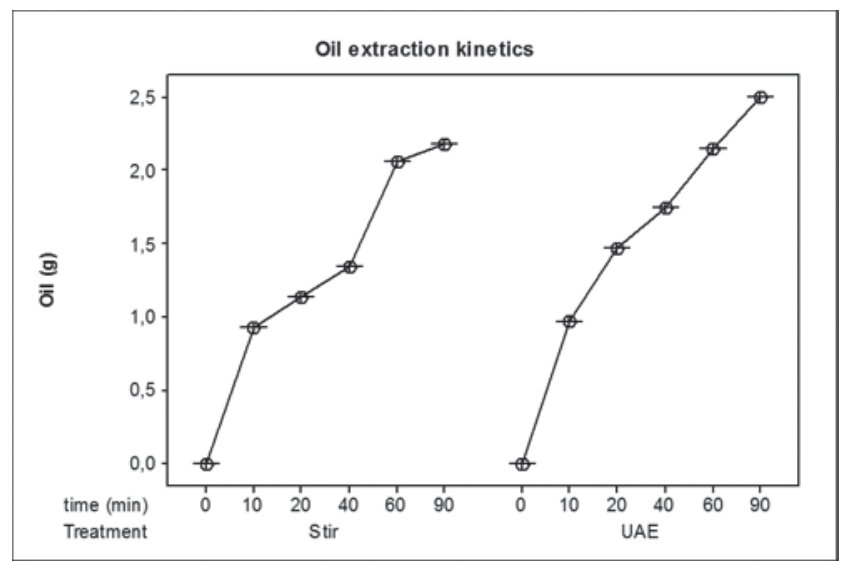

Fig. 2. Oil extraction kinetics for stir and UAE treatments.

In good agree with kinetic behaviour, the diffusion coefficient values for each treatment show that the mass transfer is accelerated in the sonicated process $\left(1.04 \times 10^{-11} \mathrm{~m}^{2} \mathrm{~s}^{-1}\right)$ being $4.5 \%$ more than the value reached in the stir extraction (9.16 x $\left.10^{-12} \mathrm{~m}^{2} \mathrm{~s}^{-1}\right)$; therefore, the extraction process and the time that is achieved are improved. As already mentioned, solvent extraction from dried material is a two-stage process, involving steeping vegetal material in solvent and then the mass transfer of soluble constituents in the material to solvent, by diffusion and osmotic mechanisms. UAE can facilitate swelling and hydration, causing an enlargement in the pores of the cell wall. This will improve the diffusion process and therefore, enhanced mass transfer. The oil mobility from chia seed to the solvent not showed great difference between treatments, although with UAE was higher, due to the cavitation phenomena and because an increase in the swelling of vegetal tissue can, in some cases, break the cell walls, which favors the washing out process [19, 22, 37]. According with Luque-García \& Luque de Castro [16], very high local temperatures increase solubility and diffusivity, and pressures that bring on penetration and transport at the interface between a liquid subjected to ultrasonic energy and a solid matrix, result in high extractive power.

Fig. 4 shown the thermograms obtained by MDSC for oils extracted, similar to that obtained by Uzunova, Nikolova, Perifanva, Gentscheva, Marudova \& Antova [13]. On heating, the melting zone was characterised by two endothermic peaks which

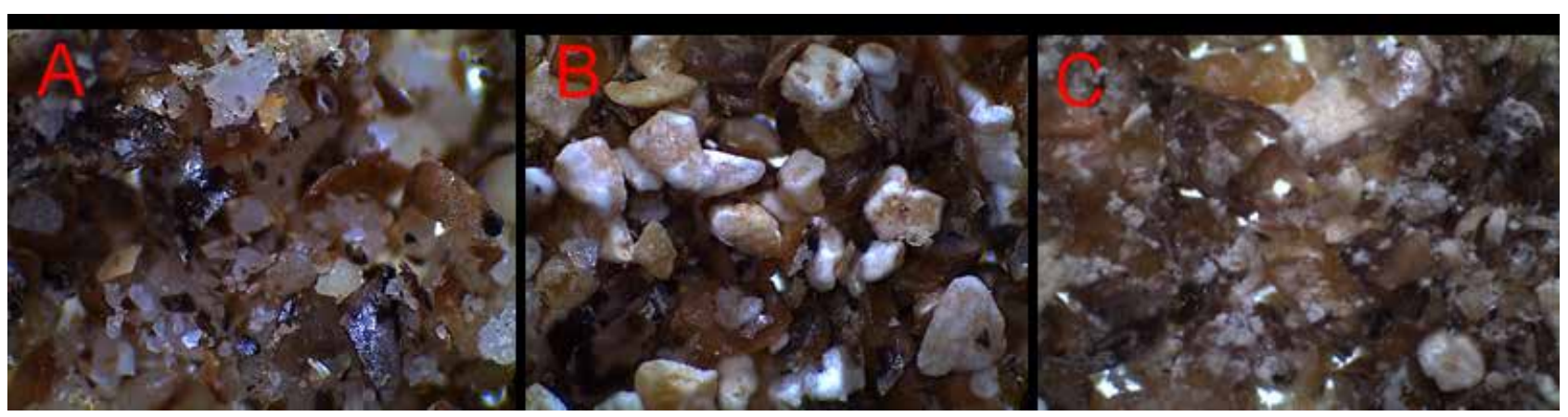

Fig. 3. Chia flour extracted with A: Soxhlet, B: Stir and C: UAE. 
consisted of a small lower temperature endotherm, between -50 and $-30{ }^{\circ} \mathrm{C}\left(\mathrm{M}_{1}\right)$, and a large higher-temperature endotherm, between -30 and $5{ }^{\circ} \mathrm{C}\left(\mathrm{M}_{2}\right)$, with several tailing shoulder endothermic peaks between 5 and $50{ }^{\circ} \mathrm{C}$. These small endotherms could be considered a discrete thermal transition from the main melting endotherm. Generally, the melting curves of oil samples complex features are not easily interpretable, such as the shoulders not separable from peaks [38]. These results illustrate the complex nature of TAG in oil samples, since Tm depends on molecular weight, the number and configuration of double bonds, stereochemistry, and the long-chain fatty compounds.

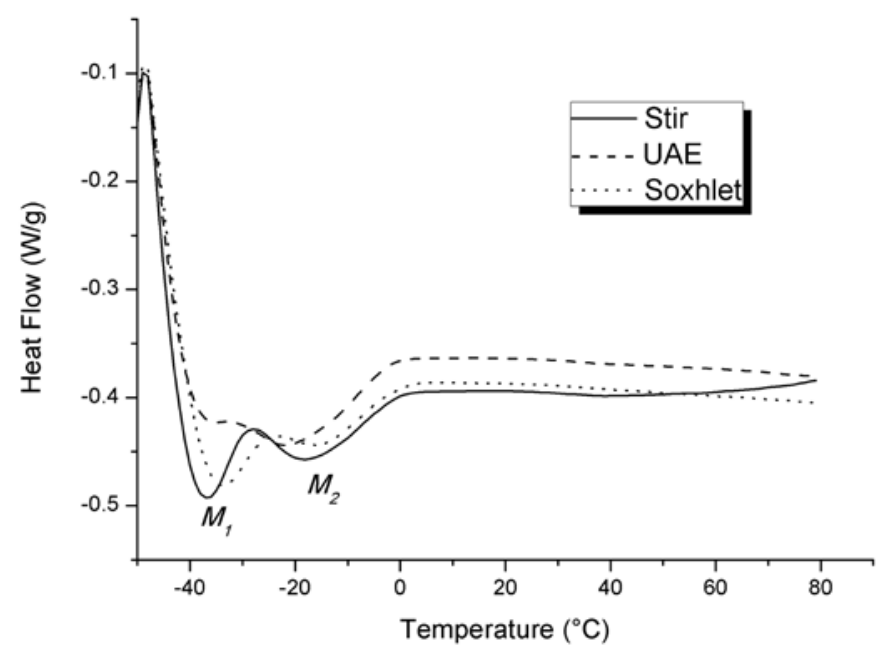

Fig. 4. MDSC thermograms of chia seed oil obtained through different methods.

In this study the major transitions were between -50 and $50{ }^{\circ} \mathrm{C}$, and correspond to the main fatty acids in the composition of chia oil. The different melting ranges and curve shapes represent the combined effects of fatty acid composition, polymorphism and thermal history of TAGs, meaning that its melting temperature estimation is complicated compared to that of most organic compounds. Chia oil contains higher proportions of unsaturated (U) and some saturated (S) fatty acids; correspondingly its mean TAG profiles: $\alpha \operatorname{Ln} \alpha \operatorname{Ln} \alpha \operatorname{Ln}, \alpha \operatorname{Ln} \alpha \operatorname{LnL}, \alpha \mathrm{L}-$ $\mathrm{nLL}, \alpha \operatorname{Ln} \alpha \operatorname{LnP}, \alpha \operatorname{LnLP}, \alpha \operatorname{LnOO}, \alpha \operatorname{LnPP}, \mathrm{LLSt}$, that also shows melting/crystallization profiles $[4,39]$. In the case of TAGs, S fatty acids are relatively linear molecules that can easily align themselves to form a compact mass. $U$ fatty acids in TAGs have twists in their aliphatic chains, which disrupt packing and hinder the formation of crystals, causing that unsaturated TAGs has a lower melting temperature than those saturated with the same chain length. So, the lowest temperature peak was due to the melting of highly unsaturated (UUU) TAGs. The second peak was due to the melting of UUS TAGs and the high temperature endotherms, when appear, was due to the minor USS groups in the sample [40-42]. According to Luque-Garcia \& Luque de Castro [16], the main advantages of UAE over conventional Soxhlet extraction are as follows: (a) Cavitation increases the polarity of the system, including solvents, analytes and matrix; this increases the extraction efficiency, which can be similar to or greater than that of conventional Soxhlet extraction, and (b) UAE allows the addition of a co-extractant to increase further the polarity of the liquid phase. As the concentration of polar compounds increased during the heating process, the compounds contributed to the changes in crystallization and melting peak parameters. It is well known that the presence of free fatty acids, partial glycerides, and oxidation products in oil tends to shift the melting range to lower temperatures [43].

On the other hand, the collapse of the cavitation bubble creates a transitory hot spot with elevated localized temperature and pressure, which can accelerate dramatically the chemical reactivity into the medium. Then, is very likely that this high temperature produce sufficient energy to break covalent $\mathrm{C}-\mathrm{C}$ or $\mathrm{C}-\mathrm{H}$ bonds in the acyl backbone to form a variety of lipid alkyl radicals [44], which after that can start the radical chain reactions of oxidation. So that, it is assumed that there was a small decrease in saturated fatty acids and an increase in unsaturated fatty acids when UAE was used, and the Tm was slightly lower. It is known that unsaturated fatty acids are more susceptible to oxidation, whereas saturated fatty acids are more stable to oxidation [45]. In the case of stir extraction, we assume that this oxidation process is initially due to dissolved air induced by stirring.

According to Hosseini et al. [46], the edible oils molecules are similar in size and shape, and flow fairly freely, but oxidation creates new and different compounds, which introduce new forces of interaction between them. Differences in major chemical components, as triacylglyceride and fatty acids, and minor chemical components, such as diacylglyceride, free acidity, and lipid oxidation products, might have affected the melting behaviour of the samples. A more ordered crystal structure might be hypothesized for untreated samples with their more uniform chemical composition compared with the sonicated oils, which resulted in a wide melting temperature range. They suggested that, as the content of oxidation products such as polar compounds, hydroperoxides, and aldehydes increased, the melting range shifted to a lower temperature, and the enthalpy decreased, as well as that the ultrasound expanded the melting range.

Table 1 resume the main transitions founded. The lowest melting temperature $(\mathrm{Tm})$ as the lowest energy requirement for melting chia oil fatty acids was for samples extracted by UAE at first peak $\mathrm{M}_{1}$, with an enthalpy difference $(\Delta \mathrm{Hm})$ about 6.5 $\mathrm{J} / \mathrm{g}$ regarding oil soxhlet extracted, and around $5 \mathrm{~J} / \mathrm{g}$ regarding stirred extracted. For $\mathrm{M}_{2}$, the oil extracted by UEA had the lowest temperature value but with the greater energy requirements for melting process. Usually, the oil samples with a high degree of saturation showed melting enthalpies at higher values, as compared to the oil samples with a high degree of unsaturation, it means with cis-double bonds. This observation is predictable since oil samples with higher degrees of saturation require more energy during the melting process [47]. Therefore, the values of $\Delta H m$ are governed by several factors such as hydrogen bonding, the molecular packing in crystals, which is influenced by molecular shape, size and symmetry, and other intermolecular interactions such as charge transfer and dipole-dipole interactions in the solid phase [38]. 
The MDSC technique is more sensitive to the individual TAG transitions, as the instantaneously superposed high heating rates allow to differentiate between phenomena related to changes in heat capacity in the reversing heat flow: such glass transition and melting; and the interfering kinetic processes in the non-reversing heat flow: such crystallization, structural perfection, decomposition, and evaporation. Therefore, most transitions in the total heat flow have components in the reversing and non-reversing heat signals, which indicate that the transitions show a combination of melting and crystallization of the respective fatty acids in the experimental temperature range. In some instances, crystallization and melting can contribute to the reversing heat flow, as a result of rapid interfacial crystallization and melting within the modulation cycle $[41,48]$. The differences in reversing and non-reversing heat flow are very clear for chia oil (Fig. 5), likely due to high amounts of polyunsaturated fatty acids that cause both chemical constraints, released during melting, and physical constraints, released during enthalpic relaxation, around unsaturated fractions. So, the melting of fatty acids is best observed in the reversing heat flow, together with endothermic relaxations in the non-reversing heat flow; the contribution of each process can be estimated from the enthalpy of both reversing and non-reversing events.

These heat flows are relatively well coupled in presence of mono-unsaturated fractions, but deviate stronger in presence of poly-unsaturated fatty acids as an indication of structural rearrangements or co-crystallization before melting [41]. This is a consequence of the known phenomenon of polymorphism of natural oils and fats that has interested researchers for many years. When a partial melting of a polymorph, accompanied by a conversion or transition to a higher polymorph takes place, both endothermic peak and endothermal changes are represented in a single endothermic peak, as can be shown in total heat flow signal in Fig.4 [38, 40, 49].

The multiple shoulder bands in the reversing heat flow (Fig. 5) show the stepwise melting of the oil structure: typically, fats crystallize first in the least stable polymorph with the lowest energy barrier $(\alpha)$ and later transform or recrystallize to steadier polymorphs $\left(\beta^{\prime}\right.$ or $\left.\beta\right)$. Direct crystallization of $\beta^{\prime}$ or $\beta$ forms from melts tends to occur only when no super-cooling, or sometimes little, of the less stable forms is present. This signal represents the thermodynamic changes; it means the structural changes, as well as the non-reversible heat flow the kinetic ones.

In most cases, the reaction enthalpy from the total heat flow equals the sum of enthalpies of reversing and non-reversing heat flows (Table 1). The enthalpy values obtained from the reversible signal for the different polymorphs in $\mathrm{M}_{1}$ also can be seen in Table 1. In general, some of the less thermally stable TAG polymorphs melt while the remaining ones rearrange and recrystallize into steadier polymorphs, which melt at higher temperatures. According to Himawan, Starov \& Stapley [40], Samyn et al. [41], and Tan \& Che Man [42], it is possible that this first melting peak corresponds to any $\alpha \operatorname{Ln} \alpha \operatorname{Ln} \alpha \operatorname{Ln}, \alpha \operatorname{Ln} \alpha \mathrm{L}-$ $\mathrm{nL}$, or $\alpha$ LnLL chia oil TAGs.

It is also well known that mixing different fatty acid fractions in a TAG produce more complex polymorphic behaviour; evidence has already been provided that melting of TAG complexes can occur simultaneously during heating in the MDSC. Therefore, in a certain temperature range, the melting of two or more TAG structures could take place together, resulting in broad or overlapping melting transitions $[36,40]$, as in $\mathrm{M}_{2}$; this behavior may be due to the presence of monounsaturated TAGs in chia oil, such as $\alpha$ Ln $\alpha$ LnP, $\alpha$ LnLP and LLSt.
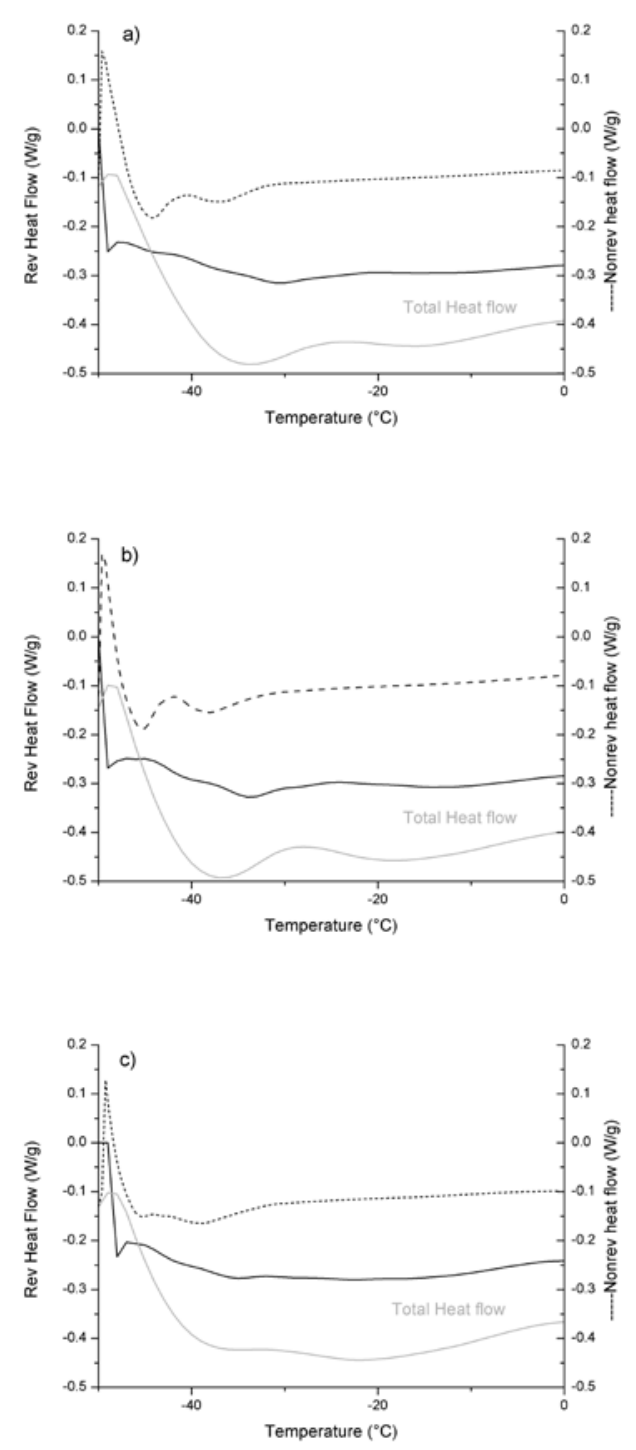

Fig.5. Heat flow deconvolution in reversible and non reversible signals for extracted samples: a) Soxhlet, b) Stir and c) UAE.

The crystallization of fats releases a considerable quantity of latent heat, as much as $200 \mathrm{~kJ} \mathrm{~kg}^{-1}$, so the polymorphic structures must be more directly reflected on the $\Delta H m$ values, since these values mean the latent heat when the crystalline phases transform to disordered neat liquid. It seems that, the more disordered in the crystal structures, the fewer values of $\Delta \mathrm{Hm}$ are obtained [40,47], as in the $\alpha$ form evaluated. This general stability behaviour can be seen in the enthalpy changes in table 1 for the polymorphs evaluated in $M_{1}$. In agreement Martini 
et al. [50], the melting profile can be explained by the smaller crystals generated during UEA. Smaller crystals have greater surface area, and they will therefore melt faster upon heating. Even though UEA generates smaller crystals, the packing of the crystals is such that a broader melting profile is obtained, as can be seen in the non-reversible signal. The lipid's melting profile of a lipid network depends on the amount of crystallized material, and the size of the crystals, among other factors [51]. These different melting profiles suggest that different polymorphic forms might be forming in the oil samples as a consequence of stirring and UEA application.

Besides the heat flow, the specific heat capacity $(\mathrm{Cp})$ is more fundamental material property and can be measured during MDSC experiment[41]. For oils with the higher degree of unsaturation, $\mathrm{Cp}$ increase with heating temperatures; this increase is theoretically explained by the heat consumption during expansion and density variations of the substance under heating [52]. By definition, the heat capacity measurements are derived from the reversible heat flow curves, so changes in melting behaviour observed as a consequence of stirring and sonication are due to different molecular interactions of the same molecular entities. Differences in enthalpy values can be attributed to the formation of different molecular compounds. The type of TAGs that form the crystalline network, the type of molecular interactions formed during crystallization such as hydrogen bonds, dipole- dipole interactions, and molecular packing affect melting enthalpy values. Therefore, any of these three reasons could be responsible for changes in enthalpy values observed as a consequence of sonication $[40,53]$ and stirring.

The relative stability of two polymorphs and the driving force for transformations between them at constant temperature and pressure are determined by their respective Gibbs free energies $(\mathrm{G})$; the polymorph which has the lowest Gibbs-free energy is the most stable. Due to its monotropic nature, the Gibbs free energy values are largest for the $\alpha$-form, having the least dense crystal packing, intermediate for the $\beta^{\prime}$-form, and smallest for the $\beta$-form, with the most dense crystal packing. This is mainly a consequence of the higher heats of fusion of polymorphs with higher melting temperature. Each polymorphic form has its own melting temperature. The presence of the double bond, with the inflexible twist, gives greater steric hindrance than found in completely saturated TAGs, which forces specific structures to be formed to enable the $\mathrm{S}$ and $\mathrm{U}$ fatty acid fractions to be packed together in the same lamella leaflet. Consequently, this TAG group exhibits still more complicated polymorphic behaviour [40]. In this study, although $\mathrm{G}$ was not evaluated, it can be assumed, for the values obtained, that the melting enthalpy decrease with the presence of more double bonds.

If the fatty acids composition might also affect oxidation, especially concerning the unsaturation degree, and a small decrease in saturated fatty acids and an increase in unsaturated fatty acids occurred when UAE was used, both the formation and the amount of primary oxidation compounds increase [55].

Results would indicate that oxidation of chia oil does occur upon application of ultrasound, suggesting that micro-mechanical shocks attributed to cavitation, affect structural and functional components up to the point of lipid oxidation and deterioration. The collapse of the bubbles leads to energy accumulation in hot spots where temperatures of above $5000{ }^{\circ} \mathrm{C}$ and pressures of approximately $500 \mathrm{MPa}$ have been measured [54]. This phenomenon can cause lipid oxidation through three mechanisms, which can act alone or combined. The first one is purely thermal, due to the high temperatures achieved during cavitation. The second one is due to free radicals and oxygen, generated by sonolysis, mediated chain reactions involving the following stages: i) abstraction of hydrogen atom, ii) formation of lipid free radical $\left(\mathrm{R}^{*}\right)$, iii) formation of lipid-peroxyl free radical (ROO*), iv) formation of lipid hydroperoxide (ROOH); and the third one is due to the mechanical shear forces created by microstreaming and

Table 1. Main transitions in chia oils extracted.

\begin{tabular}{|c|c|c|c|c|c|c|}
\hline \multirow[t]{2}{*}{ Sample } & \multirow[t]{2}{*}{ Melting peak } & \multirow{2}{*}{$\begin{array}{l}\mathrm{Tm} \\
\left({ }^{\circ} \mathrm{C}\right)\end{array}$} & \multirow{2}{*}{$\begin{array}{l}\Delta H m \\
(J / g)\end{array}$} & \multicolumn{2}{|c|}{ Polimorphs* } & \multirow{2}{*}{$\begin{array}{c}\text { Non reversible } \\
\Delta H(J / g)\end{array}$} \\
\hline & & & & $\operatorname{Tm}\left({ }^{\circ} \mathrm{C}\right)$ & $\Delta H(J / g)$ & \\
\hline Soxhlet & \multirow{3}{*}{$\mathrm{M}_{1}$} & -36.86 & 8.845 & $\begin{array}{l}\alpha=-44.33 \\
\beta^{\prime}=-41.02 \\
\beta=-31.05\end{array}$ & $\begin{array}{l}0.046 \\
0.072 \\
0.314 \\
\end{array}$ & 8.097 \\
\hline Stir & & -39.18 & 11.580 & $\begin{array}{l}\alpha=-46.81 \\
\beta^{\prime}=-40.76 \\
\beta=-33.89\end{array}$ & $\begin{array}{l}0.057 \\
0.101 \\
0.621 \\
\end{array}$ & 10.440 \\
\hline UAE & & -40.04 & 6.010 & $\begin{array}{l}\alpha=-46.65 \\
\beta^{\prime}=-41.67 \\
\beta=-35.93\end{array}$ & $\begin{array}{l}0.029 \\
0.041 \\
0.187\end{array}$ & 5.451 \\
\hline Soxhlet & \multirow{3}{*}{$\mathrm{M}_{2}$} & -14.86 & 1.142 & \multicolumn{2}{|c|}{0.345} & 0.797 \\
\hline Stir & & -16.88 & 2.946 & \multicolumn{2}{|c|}{0.089} & 2.857 \\
\hline UAE & & -19.84 & 4.214 & \multicolumn{2}{|c|}{2.082} & 2.165 \\
\hline
\end{tabular}

*Melting temperature and enthalpy obtained from reversible heat flow signal 
shock waves [55-59]. However, ultrasonication did not noticeably influence the composition of the extracted oil.

The FTIR spectra (Fig. 6), of oils extracted with and without US, present strong triplet bands in $2960-2850 \mathrm{~cm}^{-1}$ range whose is assigned to $\mathrm{C}-\mathrm{H}$ stretching of the methyl and methylene backbones of lipids. In particular, the distinctive peak at $3010 \mathrm{~cm}^{-1}$ was caused by C-H stretching of cis-olefinic $\mathrm{HC}=\mathrm{CH}-$ bonds, representing the unsaturated fatty acids. The position of this peak strongly depends on the number of conjugated $\mathrm{C}=\mathrm{C}$ double bonds in fatty acids of the analyzed oil, commonly used to determine the degree of unsaturation [60].The high degree of unsaturation observed is due to a significantly high proportion $(\sim 55 \%)$ of $\alpha$ - linolenic acid, which contains 3 conjugated $\mathrm{C}=\mathrm{C}$ double bonds in its structure.

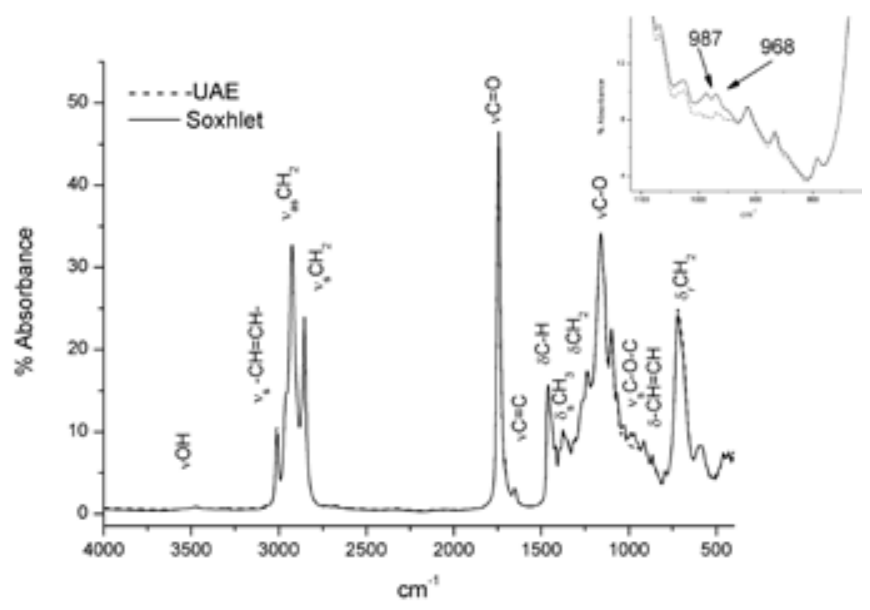

Fig. 6. FTIR spectra for chia seed oil extracted.

It should be noted that FTIR spectra did not show O-H stretching band at $\sim 3470 \mathrm{~cm}^{-1}$, indicating the presence of only a negligible amount of moisture in these oils. In the low-wavenumber region, the spectra consisted of a prominent peak at $1743 \mathrm{~cm}^{-1}$ due to $\mathrm{C}=\mathrm{O}$ carbonyl stretching of ester functional groups of lipids and fatty acids. According to Guillen \& Cabo [61] this peak provides a measure of total lipids in the analyzed oils, as the weak peak occurring at $1654 \mathrm{~cm}^{-1}$, due to $\mathrm{C}=\mathrm{C}$ stretching of disubstituted cis-olefins, can also be used to determine total unsaturation.

The overlapped bands within the range of $1470-1370 \mathrm{~cm}^{-1}$ arose due to the combination of deformation modes of methyl and methylene groups. Other strong peaks present at 1160 and $1098 \mathrm{~cm}^{-1}$ were the first band represents combined asymmetric stretching of $(\mathrm{C}-\mathrm{C}(=\mathrm{O})-\mathrm{O})$ and $(\mathrm{OC}-\mathrm{C})$ bonds, while the band at $1099 \mathrm{~cm}^{-1}$ is associated with $(\mathrm{C}-\mathrm{O}-\mathrm{C})$ symmetric stretching of triglycerides and esters. The most intense band at the lower end of the spectra centered at $720 \mathrm{~cm}^{-1}$ was attributed to the combination of rocking vibration and the out-of-plane deformation of methylene in cis-disubstituted olefins.
The only difference among spectres, from oil extracted with and without US, is in 987 and $968 \mathrm{~cm}^{-1}$ bands, the last one related to the proportion of trans olefinic groups coming from mono or polyunsaturated acyl groups $(-\mathrm{HC}=\mathrm{CH}-$ out of plane bending), and at low trans fat level, the presence of the conjugated trans/trans $18: 2$ faty acid near $990 \mathrm{~cm}^{-1}[62,63]$. These two bands almost disappear when UAE is applied, maybe due the temperature effects of cavitation that can break covalent C-C or C-H bonds [44].

Due to the capability of the FTIR spectroscopy to reveal the characteristic peak that specifically represents unsaturated fatty acids (UFAs) in the observed spectrum, this method is often used for a rapid determination of UFAs among oils. For this purpose, integrated areas under the bands at $3010 \mathrm{~cm}-1$ and $1743 \mathrm{~cm}^{-1}$ were obtained to represent UFA and total lipid content, respectively. Then, \%UFA values were calculated as the percentage of the integrated band areas at $3010 / 1743 \mathrm{~cm}^{-1}$ (i.e. UFAs per total lipids). The \%UFA result (18.88\%) showed that Chia oil contains high concentration of UFAs, that also corroborates well with the degree of unsaturation observed using the individual feature of the band at $1654 \mathrm{~cm}^{-1}[61,64]$.

\section{Conclusions}

In the main, lower precision in ultrasound-assisted processes results from the use of ultrasonic baths, in which energy distribution is not uniform and ultrasound energy is wasted. However, these drawbacks can be easily avoided by using an ultrasonic probe device.

The most probably mechanism for ultrasonic enhancement of extraction is that the waves in the vegetable material break the cells, by the collapse of cavitation bubbles producing wall disruption together with a good penetration of the solvent through the ultrasonic jet. Thus, implementation of ultrasonic treatment provided significantly higher yield with reduction in extraction time that may improve through put into the commercial oil production process.

MDSC does not provide any direct information about the chemical composition of edible oils under a given set of experimental conditions. However, it provides useful information regarding the nature of the thermodynamic changes that are associated with the edible oils transforming from one physical state to another. These thermodynamic characteristics are sensitive to the general chemical composition of edible oils and fats and thus can be used in qualitative and quantitative ways for identification of edible oils.

The TAG's chia oil content, were more influenced by the temperatures used during the extraction than by the ultrasound treatment.

The FTIR spectroscopy technique offers several advantages; in combination with the ATR technique, has shown to be a useful tool in detecting mixtures or adulterations in oils and fats. From the ratio of absorbances of olefinic and aliphatic -C-H stretching vibration bands, the degree of unsaturation of oils and fats can be determined, also from the absorbance of a single band such as the $-\mathrm{C}=\mathrm{C}$ - stretching band at $1654 \mathrm{~cm}^{-1}$ or 
the olefinic band at $3010 \mathrm{~cm}^{-1}$, although, in these cases, only cis- unsaturation is taken into account.

The factors affecting lipid degradation include energy input (light or heat), fatty acids composition, types of oxygen, and minor compounds such as metals, pigments, phospholipids, free fatty acids, mono and diacylglycerols, thermally oxidized compounds and antioxidants. All those factors are also present in the ultrasound food processing and should be carefully studied.

\section{Acknowledgments}

The authors acknowledge the financial support of the DGAPAUNAM, PAPIIT project key number IT201417 and PIAPIC 22.

\section{References}

1. Olivos-Lugo, B.L. Estudio de las propiedades térmicas, funcionales y nutritivas de la fracción proteínica de la semilla de chia (Salvia hispanica), [Unpublished Theses] Universidad Nacional Autónoma de México, Facultad de Química, México, 2005.

2. Ayerza, R., Coates, W. Trop. Sci. 2004, 44, 131-135.

3. Ayerza, R., Coates, W. Ind. Crops. Prod. 2009, 30, 321-324.

4. Ixtaina, V.Y., Martínez, M.L., Spotorno, V., Mateo, C.M., Maestri, D.M., Diehl, B.W.K., Nolasco. S.M., Tomás, M.C. J. Food Compost. Anal. 2011, 24, 166-174.

5. Martínez, M.L., Marín, M.A., Salgado- Faller, C.M., Revol, J., Penci, M.C., Ribotta, P.D. Lebensm Wiss Technol. 2012, 47, 78-82.

6. Castejón, N., Luna, P., Señoráns, F.J. J. Agric. Food Chem. 2017, 65, 2572-2579.

7. Timilsena, Y.P., Adhikari, R., Barrow, C.J., Adhikari, B. J Biol Macromol. 2016, 91,347-357.

8. Silva, C., Garcia, V.A.S. Zanette, C.M. Int Food Res J. 2016, 23(3), 998-1004.

9. Segura-Campos,M.R., Ciau-Solís, N., Rosado-Rubio, G., Chel-Guerrero, L. Betancur-Ancona, D. Agric. Sci. 2014, 5(3), 220-226.

10. Nemes, S.M., Orsat, V. Food Anal. Methods, 2012, 5, 551-563.

11. Uribe, J.A.R., Perez, J.I.N., Kauil, H.C., Rubio, G.R. Alcocer, C.G. J. Supercritl Fluids. 2011, 56, 174-178.

12. Coelho, M.S., Salas-Mellado, M.M. J Food and Nut Res. 2014, 2(5), 263-269.

13. Uzunova G., Nikolova Kr., Perifanova M., Gentscheva, G., Marudova, M., Antova, M,1. Bulgarian Chemical Communications, 2016, 48G, 131-135.

14. Soria, A.C., Villamiel, M. Trends Food Sci. Technol. 2010, 21, 323-331.

15. De Mello, B.T.F., Dos Santos Garcia, V.A., Da Silva, C. J Food Process Eng. 2017, 40, e12298.

16. Luque-García, J.L., Luque de Castro, M.D. TrAC Trends in Analyt. Chem. 2003, 22, 41-47.

17. Robles, L.E., Ochoa, L.A. Rev. Iber Tecnología Postcosecha. 2012, 13, 109-122.

18. Romdhane, M., Gourdan, C. Chem. Eng. J. 2002, 87, 11-19.

19. Vinatoru, M. Sonochem. 2001, 8, 303-313.
20. Vilkhu, K., Mawson, R., Simons, L., Bates, D. Innov. Food Sci. Emerg. 2008, 9, 161-169.

21. Srikaeo, K., Furst, J.E., Ashton, J.F., Hosken, R.W., Sopade, P.A. Carbohydr. Polym. 2005, 61, 203-210.

22. Tan, C.P., Che Man, Y.B. Food Chem. 2002, 76, 89-102.

23. Cedeño, F.C., Prieto, M.M., Espina, A., García, J.R. Thermochim. Acta. 2001, 369, 39-50.

24. Alvarez-Chávez, L.M., Valdivia-López, M.A., Aburto-Juárez, M.L., Tecante, A. Int. J. Food Prop. 2008, 11, 687-697.

25. Ayerza, R. J. Am. Oil Chem. Soc. 1995, 72, 1079-1081.

26. Gutiérrez-Tolentino, R., Ramírez-Vega, M.L., Vega y León, S., Fontecha, J., Rodríguez, L.M., Escobar Medina, A. Revista Cubana de Plantas Medicinales. 2014, 19, 199-207.

27. Kačuráková, M., Mathlouthi, M. Carbohyd. Res. 1996, 284, 145-157.

28. Mossoba, M.M., Kramer, J.K.G., Azizian, H., Kraft, J., Delmonte, P., Kia, A.R.F., Bueso. F.J., Rader, J.I., Lee, J.K. J. Am. Oil Chem. Soc. 2012, 89, 419-429.

29. Rastogi, N.K., Raghavarao, K.S.M.S. Lebensm Wiss Technol. 2004, 37, 43-47.

30. Martínez-Navarrete, N., Andrés, A.M., Chiralt, A., Fito, M.P. Termodinámica y cinética de sistemas alimento entorno. Universidad Politécnica de Valencia. Servicio de Publicacion, España,1999.

31. Gogate, P.R., Kabadi, A.M. Biochem. Eng. J. 2009, 44, 60-72.

32. Vinatoru, M., Toma, M., Radu, O., Filip, P.I., Lazurca, D., Mason, T.J. Ultrason. Sonochem. 1997, 4, 135-139.

33. Zhang, Z.S., Wang, L.J., Li, D., Jiao, S.S., Chena, X.D., Maoa, Z.H. Sep. Purif. Technol. 2008, 6, 192-198.

34. Chemat, F., Zill-e-Huma, Khan, M.K. Ultrason. Sonochem. 2011, 18, 813-835.

35. Muñoz, L.A., Cobos, A., Diaz, O., Aguilera, J.M. J. Food Eng. 2012, 108, 216-224.

36. Capitani, M.I., Spotorno, V., Nolasco, S.M., Tomás, M.C. Lebensm Wiss Technol. 2012, 45, 94-102.

37. Toma, M., Vinatoru, M., Paniwnyk, L., Mason, T.J. Ultrason. Sonochem. 2001, 8, 137-142.

38. Tan, C.P, Che Man, Y.B. J. Am. Oil Chem. Soc. 2000, 77, 144-155.

39. Ixtaina, V.Y. Caracterización de la semilla y el aceite de chia (Salvia hispánica) obtenido mediante distintos procesos. Aplicación en tecnología de alimentos [Unpublished Theses] Universidad Nacional de la Plata. Facultad de ciencias exactas, Argentina, 2010.

40. Himawan, C., Starov, V.M., Stapley, A.G.F. Adv. Colloid Interfac. 2006, 122, 3-33.

41. Samyn, P., Schoukens, G., Vonck, L., Stanssens, D., Van den Abbeele, H. J. Therm. Anal. Calorim. 2012, 110, 1353-1365.

42. Tan, C.P., Che Man, B. Phytochem. Analysis. 2002b, 13, 129-141.

43. Tan, C.P., Che Man, B. J. Am. Oil Chem. Soc. 1999, 76, 1047-1057.

44. Nawar, W.W. J. Agr. Food Chemistry. 1969, 17, 18-21.

45. Li, H., Pordesimo, L., Weiss, J. Food Res. Int. 2004, 37, 731-738.

46. Hosseini, S., Gharachorloo, M., Tarzi, B.G., Ghavami, M., Bakhoda, H. J. Am. Oil Chemi. Soc. 2015, 92, 1717-1724.

47. Ueno, S., Miyazaki, A., Yano, J., Furukawa, Y., Suzuki, M., Sato, K. Chem. Phys. Lipids. 2000, 107, 169-178.

48. Wunderlich, B., Okazaki, I., Ishikiriyama, K., Boller, A. Thermochim. Acta. 1998, 324, 77-85.

49. Desmedt, A., Culot, C., Deroanne, Durant, F., Glbon, V. J. Am. Oil Chem. Soc. 1990, 67, 653-660. 
50. Martini, S., Tejeda-Pichardo, R., Ye, Y., Padilla, S.G., Shen, F.K., Doyle, T. J. Am. Oil Chem. Soc. 2012, 89, 1921-1928.

51. Suzuki, A.H., Lee, J., Padilla, S.G., Martini, S. J. Food Sci. 2010, 75, E208-E214.

52. Fasina, O.O., Colley, Z. Int. J. Food Prop. 2008, 11, 738-746.

53. Lee, J., Ye, Y., Martini, S. J. Am. Oil Chem. Soc. 2015, 92, 305-308.

54. Povey, M.J.W., Mason, T.J. Ultrasound in Food Processing. Blackie Academic and Professional, London, 1998.

55. Chatterjee, S.N., Agarwal, S. Free Radical Bio. Med. 1998, 4, 51-72.

56. Chemat, F., Grondin, I., Costes, P., Moutoussamy, L., Shum, C.A., Sing, J., Smadja. Ultrason. Sonochem. 2004, 11, 281-285.

57. Choe, E., Min, D.B. Compr. Rev. Food Sci. 2006, 5, 169-186.
58. Jana, A.K., Agarwal, S., Chatterjee, S.N. J. Bioscience. 1990, 15, 211-215.

59. Pingret, D., Fabiano-Tixier, A.S., Chemat, F. Food Control. 2013, 31, 593-606.

60. Vongsvivut, J., Miller, M.R., McNaughton, D., Heraud, Ph., Barrow, C.J. Food Bioprocess Technol. 2014, 7, 2410-2422.

61. Guillén, M.D., Cabo, N. J. Am. Oil Chem. Soc. 1997, 74, 1282-1285.

62. Mossoba, M., Milosevic, V., Milosevic, M., Kramer, J.K.G., Azizian, H. Anal. Bioanal. Chem. 2007, 389, 87-92.

63. Guillén, M.D., Cabo, N. J. Sci. Food Agric. 1997b, 75, 1-11.

64. Timilsena, Y.P., Vongsvivut, J., Adhikari, R., Adhikari, B. Food Chem. 2017, 228, 394-402. 